\title{
Air Purification by Catalytic Oxidation in a Reactor with Periodic Flow Reversal
}

\author{
Bert van de Beld and K. Roel Westerterp*
}

Dedicated to Professor Dr. Dr. h.c. Hanns Hofmann on the occasion of his 70th birthday

\begin{abstract}
The behaviour of an adiabatic packed bed reactor with periodic flow reversal has been studied by means of model calculations. A heterogeneous model as well as a pseudo-homogeneous model have been developed. It is shown that a high degree of conversion can be obtained in an autothermal process even with very low adiabatic temperature rises of some 10 to $20 \mathrm{~K}$. The reactor is insensitive to fluctuations in inlet concentrations and in throughput. Short-cut methods proposed in the literature for calculating the plateau temperature in the pseudo-steady state are studied. The so called countercurrent-flow reactor approach showed reasonable agreement with the plateau temperature obtained by dynamic calculations with the full reactor model.
\end{abstract}

\section{Introduction}

Exhaust air from laboratories, from factory buildings and from tank farms during filling of the tanks can be contaminated with variable amounts of organic substances. To prevent environmental pollution this air has to be purified. One method suitable for cleaning waste air is catalytic combustion. This method has a number of advantages compared to ad- and absorption processes: there is no need for energy consuming desorptions and treatment of residues and different compounds with varying chemical compositions can be converted. Compared to thermal combustion, catalytic oxidation consumes less energy and, due to lower temperatures, less $\mathrm{NO}_{\mathrm{x}}$ is produced.

In recent years the distinct advantages of operating a reactor under non-steady-state conditions have been demonstrated. Boreskov et al. [1] introduced the purification of waste air by catalytic oxidation in an adiabatic packed bed reactor with periodic flow reversal. The reactor is thus operated under transient conditions. The packed bed then acts as a regenerative heat exchanger due to the high heat capacity of the solid phase and, moreover, an autothermal process is possible even at very low contaminant concentrations. Other advantages of operating a process under transient conditions are summarised by Matros [2-4]. Several authors have studied the applicability of a reverse flow reactor for the purification of waste air, see e.g. Matros et al. [5], Eigenberger and Nieken [6, 7], Chumachenko and Matros [8], Noskov and Ivanov [9] and Sapundzhiev et al. [10].

\footnotetext{
* Ir. B. van de Beld and Prof. Dr. Ir. K. R. Westerterp (author to whom correspondence should be addressed), Chemical Reaction Engineering Laboratories, Department of Chemical Engineering, University of Twente, P.O. Box 217, 7500 AE Enschede, The Netherlands.
}

The principle of reversing the direction of the flow can also be applied advantageously to reversible reactions, because a more optimal temperature profile can be realised and the overall conversion can be increased. Zagoruiko [11] studied the well known Claus process in a reverse flow reactor and Neophytides and Froment [12] studied methanol synthesis under non-steady-state conditions. The same process was modelled by Thullie and Burghardt [13]: they proposed a multiple stage reactor configuration to approach the optimal temperature profile. Boreskov et al. [14], Bunimovich et al. [15], Silveston et al. [16] and Sapundzhiev et al. [17] studied the oxidation of $\mathrm{SO}_{2}$ under transient conditions and found the conversion to increase by several percent above the equilibrium conversion at the maximum temperature in the bed.

In the literature different models have been proposed to describe the behaviour of a reverse flow reactor. Eigenberger and Nieken $[6,7]$ used a pseudo-homogeneous model with axial dispersion of heat to describe it for the purification of waste air. They discussed the influence of kinetics, inert material, axial dispersion and cycle period on the reactor behaviour. Gawdzik and Rakowski $[18,19]$, Silveston et al. [16] and Thullie and Burghardt [13] used a heterogeneous model without axial dispersion of heat. Bhatia [20] used a similar model and he also considered intra-particle mass transfer resistances. A heterogeneous model with axial dispersion of heat was used by Boreskov et al. [21], Matros et al. [5], Sapundzhiev et al. [10, 17] and Young et al. [22].

\section{Mathematical Model}

To study the behaviour of a reverse flow reactor, a heterogeneous model as well as a pseudo-homogeneous model 
with axial dispersion of heat have been developed. To this end the following assumptions were made:

- The time-dependent terms in the mass balances and the gas phase heat balance can be neglected. Gawdzik and Rakowski [18] showed this assumption does not have a significant influence on the calculated profiles in a reverse flow reactor.

- The reactor pressure is constant throughout the reactor.

- The gas is in plug flow, the influence of flow nonuniformities is negligible.

- Temperature and concentration gradients within a catalyst pellet can be neglected.

- The combustion kinetics of different components are independent and are of first order in the organic compound.

Now the following dimensionless equations are obtained for the heterogeneous model: ${ }^{1}$

Solid phase heat balance:

$\frac{\partial \theta_{\mathrm{s}}}{\partial \tau}=\mathrm{NTU}_{\mathrm{h}}\left(\theta_{\mathrm{g}}-\theta_{\mathrm{s}}\right)+D a \Delta \theta_{\mathrm{ad}} \Sigma r_{\mathrm{j}}^{*} H_{\mathrm{j}}^{*}$

\section{Gas phase heat balance:}

$0=-\frac{\partial \theta_{g}}{\partial \omega}-\mathrm{NTU}_{\mathrm{h}}\left(\theta_{\mathrm{g}}-\theta_{\mathrm{s}}\right)+\frac{1}{\mathrm{Pe}_{\mathrm{h}}^{\mathrm{H}}} \frac{\partial^{2} \theta_{\mathrm{g}}}{\partial \omega^{2}}$

Solid phase mass balance for component $j$ :

$0=\mathrm{NTU}_{\mathrm{mj}}\left(y_{\mathrm{gj}}-y_{\mathrm{sj}}\right)-\mathrm{Da} r_{\mathrm{j}}^{*}$ for $j=1 \ldots k$

Gas phase mass balance for component $j$ :

$0=-\frac{\partial u_{\mathrm{g}} y_{\mathrm{gj}}}{\partial \omega}+\frac{1}{\mathrm{Pe}_{\mathrm{m}}} \frac{\partial^{2} y_{\mathrm{gi}}}{\partial \omega^{2}}-\mathrm{NTU}_{\mathrm{mj}}\left(y_{\mathrm{gj}}-y_{\mathrm{sj}}\right) \quad$ for $j=1 \ldots k$

where $k$ is the number of components present in the feed gas.

\section{Boundary conditions:}

$\omega=0^{-}, \quad \theta_{\mathrm{g}}-\theta_{0}=\frac{1}{\mathrm{Pe}_{\mathrm{h}}^{\mathrm{H}}} \frac{\partial \theta_{\mathrm{g}}}{\partial \omega}, \quad y_{\mathrm{gj}}-y_{\mathrm{gj}}^{0}=\frac{1}{\mathrm{Pe}_{\mathrm{m}}} \frac{\partial y_{\mathrm{gj}}}{\partial \omega}$

$\omega=1^{+}, \frac{\partial \theta_{\mathrm{g}}}{\partial \omega}=0, \frac{\partial y_{\mathrm{gj}}}{\partial \omega}=0$

The boundary conditions are taken outside the reactor to ensure that these conditions do not have any influence on the calculated profiles. Dimensionless groups used in the above equations are:

1) List of symbols at the end of the paper.
$\theta_{\mathrm{g}}=\frac{T_{\mathrm{g}}}{T_{0}}, \quad \omega=\frac{z}{L}, \quad \tau=\frac{u_{\mathrm{g} 0} t}{\varepsilon L} \frac{1}{F}, \quad r_{\mathrm{j}}^{*}=\frac{r_{\mathrm{j}}}{r_{1}^{0}}$

$H_{\mathrm{j}}^{*}=\frac{H_{\mathrm{j}}}{H_{1}}, \quad y_{\mathrm{jg}}=\frac{C_{\mathrm{jg}}}{C_{1}^{0}}, \quad y_{\mathrm{js}}=\frac{C_{\mathrm{j} s}}{C_{1}^{0}}, \quad \tau_{\mathrm{c}}=\frac{u_{\mathrm{g} 0} t_{\mathrm{c}}}{\varepsilon L} \frac{1}{F}$

$\Delta \theta_{\mathrm{ad}}=\frac{H_{1} C_{1}^{0}}{\left(\varrho C_{\mathrm{p}}\right)_{\mathrm{g}} T_{0}}, \quad \mathrm{NTU} \mathrm{m}_{\mathrm{mj}}=\frac{k_{\mathrm{gj}} a_{\mathrm{p}}(1-\varepsilon) L}{u_{\mathrm{g} 0}}$

$\mathrm{NTU}_{\mathrm{h}}=\frac{\alpha a_{\mathrm{p}}(1-\varepsilon) L}{\left(\varrho C_{\mathrm{p}}\right)_{\mathrm{g}} u_{\mathrm{g} 0}}, \quad \mathrm{Da}=\frac{r_{1}^{0} L}{u_{\mathrm{g} 0} C_{1}^{0}}$

$\mathrm{Pe}_{\mathrm{h}}^{\mathrm{H}}=\frac{\nu_{\mathrm{g} 0}\left(\varrho_{0} C_{\mathrm{p}}\right)_{\mathrm{g}} L}{\lambda_{\mathrm{eff}}}, \quad \mathrm{Pe}_{\mathrm{m}}=\frac{\nu_{\mathrm{g} 0} L}{D_{\mathrm{eff}}}, \quad F=\frac{(1-\varepsilon)\left(\varrho C_{\mathrm{p}}\right)_{\mathrm{s}}}{\varepsilon\left(\varrho C_{\mathrm{p}}\right)_{\mathrm{g}}}$

The pseudo-homogeneous model is derived by using the same assumptions. Now also interparticle heat- and mass transfer are neglected. To correct the model for the latter assumption the equivalence theory as proposed by Vortmeyer and Schaefer [23] has been applied. According to this theory the interparticle heat transfer can be accounted for by introducing an additional term for the axial dispersion of heat. In this case the following relation is obtained for the Peclet number, $\mathrm{Pe}_{\mathrm{h}}^{\mathrm{PH}}$, of the pseudo-homogeneous model:

$\frac{1}{\mathrm{Pe}_{\mathrm{h}}^{\mathrm{PH}}}=\frac{1}{\mathrm{Pe}_{\mathrm{h}}^{\mathrm{H}}}+\frac{1}{\mathrm{NTU}_{\mathrm{h}}}$

This expression is applicable if $\frac{d^{2} \theta_{g}}{d \omega^{2}}=\frac{d^{2} \theta_{s}}{d \omega^{2}}$ holds and if also the term $\frac{1}{\mathrm{Pe}_{\mathrm{h}}^{\mathrm{H}} \mathrm{NTU}_{\mathrm{h}}} \frac{\mathrm{d}^{3} \theta_{\mathrm{g}}}{d \omega^{3}}$ is negligible. To correct the pseudo-homogeneous model for possible mass transfer limitations an apparent reaction rate $r_{\mathrm{j}}$ has been used:

$r_{\mathrm{j}}=\left(\frac{1}{k_{\mathrm{gj}}(1-\varepsilon) a_{\mathrm{p}}}+\frac{1}{k_{\mathrm{r}}}\right)^{-1} C_{\mathrm{j}}$.

The reactor operates under non-steady-state conditions, but after a great number of cycles a pseudo-steady state (PSS) is reached; the maximum temperature as well as the distances between the heat fronts in the in- and outlet section remain constant and therefore the heat of reaction can only be removed from the reactor by an increase in temperature of the outlet stream compared to the inlet temperature. In the PSS the following overall heat balance should be satisfied:

$\bar{\theta}_{\text {out }}=\frac{2}{\tau_{\mathrm{c}}} \int_{0}^{1 / 2 \tau_{\mathrm{c}}} \theta_{\text {out }}(\tau) \mathrm{d} \tau=\theta_{0}+\mathrm{x}_{\mathrm{t}} \Delta \theta_{\mathrm{ad}}$

where $\tau_{\mathrm{c}}$ is the time period of a cycle. A cycle period consists of half a cycle upflow and half a cycle downflow. Thus in one cycle period the flow is reversed twice.

Approximation of the pseudo-steady-state is of particular interest when investigating the behaviour of a reverse flow reactor. Performing dynamic calculations with the full dy- 
namic model consumes much computer time. Therefore we studied various methods proposed in the literature for the approximation of the PSS. The first method was developed by Boreskov et al. [24] and used by Chumakova and Zolotarskii [25] to study multiplicity features in a reverse flow reactor. This method, referred to as an analysis of the sliding regime or a relaxed steady state, assumes that for short cycle periods the actual temperature and concentration profiles can be approximated by the profiles averaged over a cycle period. An analytical expression is derived for the maximum temperature in the PSS, the plateau temperature:

$$
\theta_{\text {plateau }}=\sqrt{\frac{1}{2} \frac{\theta_{\mathrm{act}} \Delta \theta_{\mathrm{ad}}\left(\mathrm{NTU}_{\mathrm{m}}+\mathrm{Da}\right)}{\frac{1}{\mathrm{Pe}_{\mathrm{h}}^{\mathrm{H}}}+\frac{1}{\mathrm{NTU}_{\mathrm{h}}}}} .
$$

Boreskov et al. [21] and Matros [26, 27] derived an approximation of the maximum temperature from an analysis of the heat front in developing the second method:

$$
\theta_{\text {plateau }}=\sqrt{\frac{\theta_{\mathrm{act}} \Delta \theta_{\mathrm{ad}}\left(\mathrm{NTU}_{\mathrm{m}}+\mathrm{Da}\right)}{\frac{1}{\mathrm{Pe}_{\mathrm{h}}^{\mathrm{H}}}+\frac{1}{\mathrm{NTU}_{\mathrm{h}}}\left(1-\frac{\Delta \theta_{\mathrm{ad}}}{\theta_{\text {plateau }}-1}\right)}} .
$$

Application of Eqs (9) and (10) is limited to specific cases where only one component is present in the reactor feed, the reaction rate is described by first order kinetics and the reactor does not contain inert material before and after the catalyst bed. Further blow-out of the reactor cannot be described properly.

The third method we studied, viz. the Countercurrent Reactor Model (CCR), was proposed by Eigenberger and Nieken [28]. A schematic drawing of the system described by this model is shown in Fig. 1. It is assumed that one half of the flow enters the reactor on one side and the other half on the other side. Or, in other words, this system contains two channels, with gas 1 flowing through the lower channel and gas 2 flowing through the upper channel in the opposite direction; the solid phase forms the wall between these two channels. The CCR model comprises a heat balance for the solid phase, heat balances for gases 1 and 2 and two gas phase mass balances and two solid phase mass balances for each component. This model can be used for more than one component and for different kinetic equations, and also includes the influence of inert material. It provides an estimate of the complete temperature and conversion profiles and it is able to predict blow-out of the reactor. It is necessary to solve all mass- and energy balances and the influence of the cycle period is not included.

\subsection{Numerical Method}

The heterogeneous model, the pseudo-homogeneous model as well as the CCR were solved numerically. In the literature

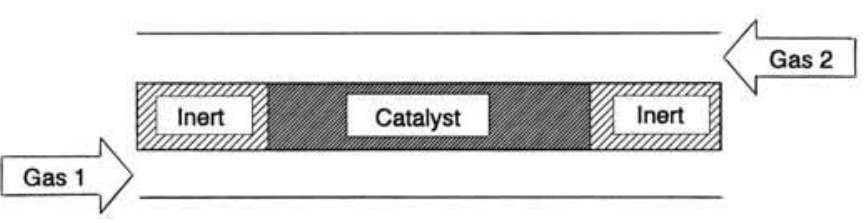

Fig. 1. Schematic drawing of the system described by the Countercurrent Reactor (CCR) model.

several methods are used to solve the set of partial differential equations. Bhatia [20] proposed a perturbation technique to save computer time, Gawdzik and Rakowski [18, 19] used the method of characteristics and a collocation technique. We decided to use a finite difference method with both an equidistant and a non-equidistant grid to solve Eqs (1) - (5). According to Khanna and Seinfeld [29], steep gradients, such as appear in a reverse flow reactor, can be handled quite well by this technique. Additional advantages of the finite difference technique are the flexibility and simplicity of its implementation in a program. In the simulations about 200 to 250 equidistant grid points were sufficient. For most simulations the ratio of real time to used computer time varies from 10 to 30 on a PC 386-33. Solving the CCR model takes only a few seconds. For further details, see Appendix A.

\section{Results}

Table 1 lists the basic set of process parameters. These were used in the simulations unless different values are mentioned. We investigated the influence of several process parameters, e.g. axial dispersion, kinetics, inert material etc., and obtained the same results as Eigenberger and Nieken [6]. Fig. 2 shows the development of the temperature profiles as a function of the number of flow reversals. Depending on the initial conditions, the pseudo-steady state is reached after 100 to 200 cycles. This is also shown in Fig. 3. It can be seen that in this case after 150 flow reversals the maximum temperature remains constant. The overall heat balance is satisfied, such that all the heat produced in the

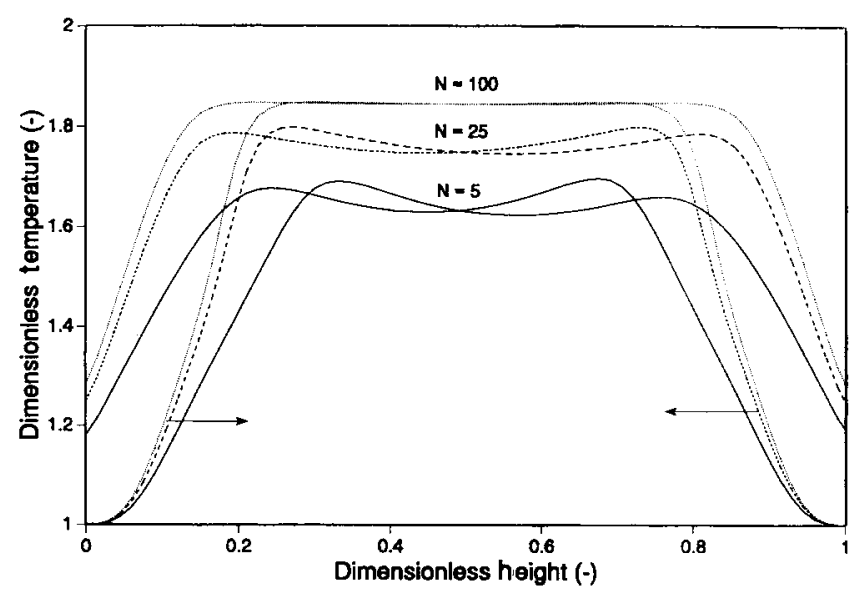

Fig. 2. Development of axial temperature profiles in a reverse flow reactor as a function of the number of reversals; conditions see Table 1 . 
Table 1. Basic set of process parameters.

\begin{tabular}{lclcl}
\hline $\mathrm{Pe}_{\mathrm{h}}^{\mathrm{H}}$ & 324.3 & $T_{0}$ & 293 & $\mathrm{~K}$ \\
$\mathrm{Pe}_{\mathrm{h}}^{\mathrm{PH}}$ & 103.5 & $P$ & 1.0 & $\mathrm{bar}$ \\
$\mathrm{NTU}_{\mathrm{h}}$ & 152.1 & $E_{\mathrm{act}}$ & 102.1 & $\mathrm{~kJ} / \mathrm{mol}$ \\
$\mathrm{Da}$ & $2.5 \times 10^{-8}$ & $k_{\infty}$ & $1.2 \times 10^{11}$ & $\mathrm{l} / \mathrm{s}$ \\
$\mathrm{NTU}_{\mathrm{m}}$ & 102.1 & $\Delta T_{\mathrm{ad}}$ & 34.2 & ${ }^{\circ} \mathrm{C}$ \\
$\mathrm{Pe}_{\mathrm{m}}$ & 324.3 & $u_{\mathrm{g} 0}$ & 0.40 & $\mathrm{~m} / \mathrm{s}$ \\
$F$ & 1700 & $L$ & 1.0 & $\mathrm{~m}$ \\
$\tau_{\mathrm{c}}$ & 0.20 & Inert packing & 30 & $\%$ \\
Compound & Propane & & &
\end{tabular}

adiabatic bed reactor is carried away in the off-gas as sensible heat.

Fig. 4 presents a comparison between the heterogeneous and the pseudo-homogeneous model. The profiles calculated with both models correspond well. Differences occur mainly in the reaction zone, where it is doubtful whether the equivalence criteria are fulfilled. For a low adiabatic temperature rise the temperature differences between gas and solid phases are small; consequently both models perform equally well.

The influence of pressure on the behaviour of the reverse flow reactor is given in Fig. 5. On increasing the pressure, the ratio of the heat capacities of the solid phase to that of the gas phase decreases and thus the ratio between the gas and the heat velocity front decreases (see Eigenberger and Nieken [28]). At constant Reynolds number the reactor behaviour does not change significantly (see Fig. 5). With increasing pressure the ratio of the residence time and the maximum allowable cycle period decreases, so an increasing amount of the feed will leave the reactor at the moment of reversal, because part of the hold-up of the bed and the piping is switched to the outlet without being converted. Operating a reverse flow reactor under elevated pressures is not so attractive.

In practice the feed composition can fluctuate with time and the chemical nature of the components may also change. Fig. 6 presents the results of simulations for a feed gas con-

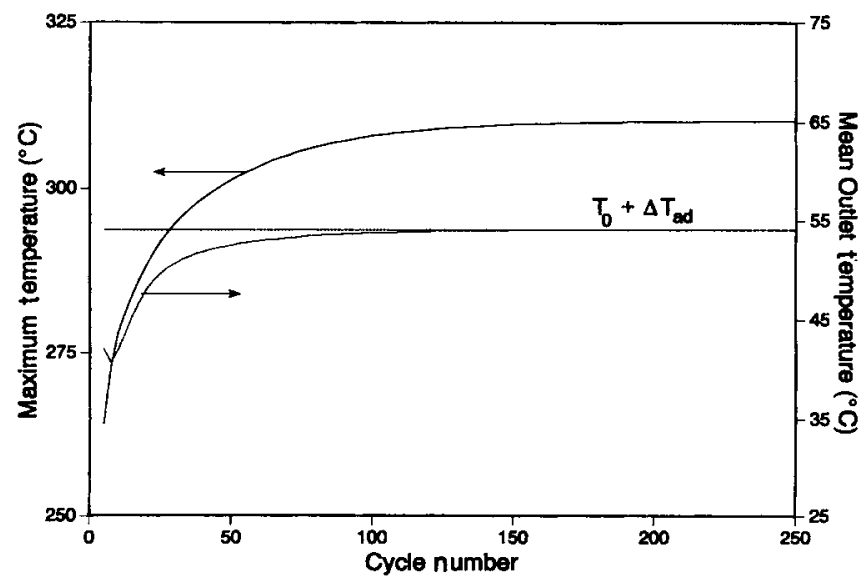

Fig. 3. Mean outlet temperature and maximum temperature as a function of the number of reversals; conditions see Table 1.

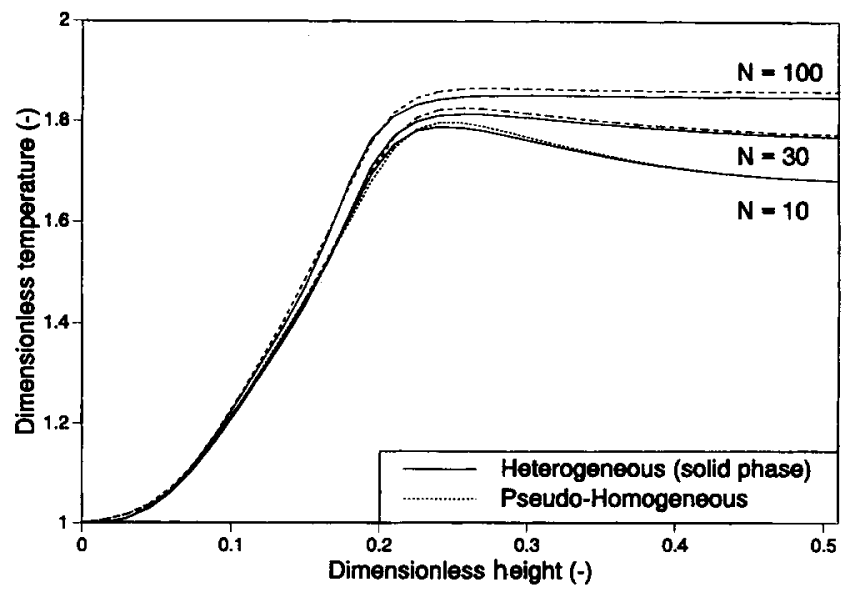

Fig. 4. Axial temperature profiles as calculated from the pseudo-homogeneous and heterogeneous model for different numbers of reversals $N$; conditions see Table 1 .

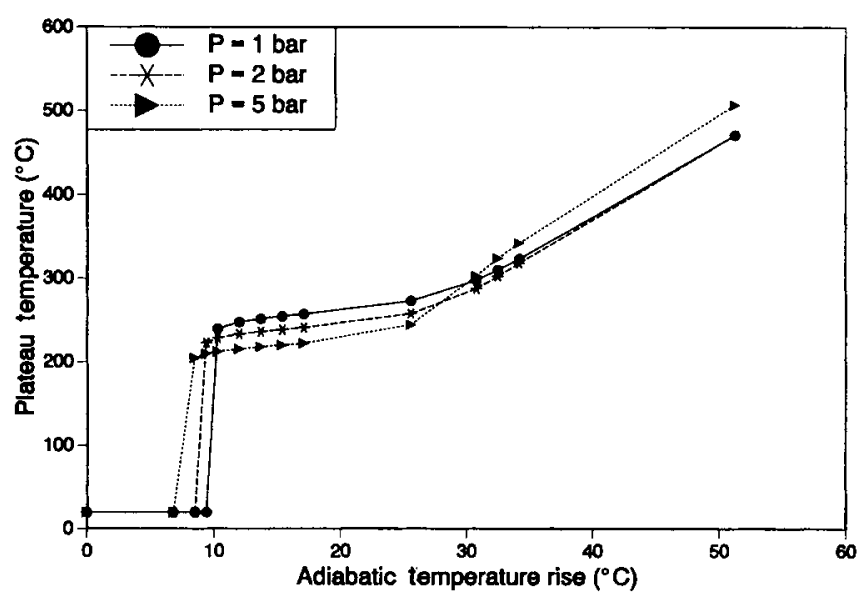

Fig. 5. The plateau temperature in the PSS as a function of the adiabatic temperature rise at different reactor pressures and for a constant Reynolds number: For conditions see Table 1.

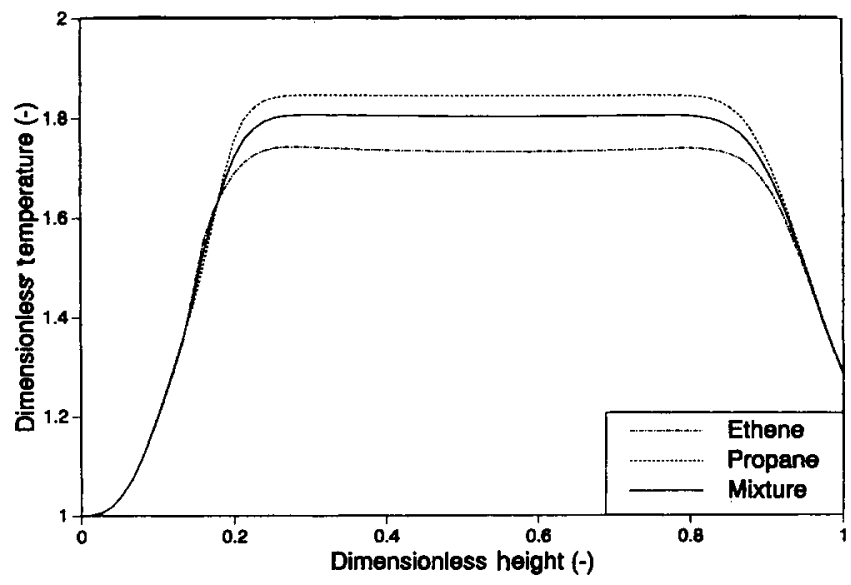

Fig. 6. Axial temperature profiles in the PSS for ethene and propane and a mixture of these compounds. All three compositions have $\Delta T_{\text {ad }}=34.2 \mathrm{~K}$. Ethene kinetics. $E_{\text {act }}=66.1 \mathrm{~kJ} / \mathrm{mol}, k_{\infty}=2 \times 10^{10}$ $\mathrm{s}^{-1}$, for propane and other conditions see Table 1 . 
taining only propane or ethylene and for a mixture of these two components. The inlet concentrations are chosen such that the adiabatic temperature rise was the same for all three simulations. The pseudo-steady-state temperature profile for the mixture lies between those of the pure components. Barresi et al. [30] and Barresi and Baldi [31] have shown for the catalytic oxidation of aromatic hydrocarbon mixtures that the different components can interact. Here we assumed that the reactions are completely independent and do not influence their individual reaction rates, e.g., by chemisorption. If this is not the case, the behaviour of the reverse flow reactor is influenced substantially.

In practice also the feed flow may fluctuate. In Fig. 7 the plateau temperature is given as a function of the superficial gas velocity and for different values of the effective axial dispersion coefficient. A maximum is observed in the curves and the position of the maximum shifts to higher gas velocities with increasing axial dispersion coefficient. The position of the maximum is important for the design of a reverse flow reactor, because on the right hand of the maximum the reactor is less sensitive to variations in the feed flow. The maximum of the plateau temperature as a function of the gas velocity can be explained as follows. At low gas velocities the main transport mechanism for heat is axial dispersion. With increasing gas velocity, axial dispersion becomes less important and the plateau temperature will increase. At high gas velocities the main transport mechanism is interparticle heat transport; this process is less efficient at higher gas velocities, so the plateau temperature will decrease. Consequently at low gas velocities the plateau temperature increases and at high gas velocities the plateau temperature decreases with increasing gas velocity, and a maximum is observed in between. Simulations demonstrate that for a constant axial dispersion coefficient, but for different adiabatic temperature rises, the position of the maximum of the curves is located at the same gas velocity, whereas the maximum becomes more pronounced. These observations coincide with the explanation given above. Changing the heat transfer coefficient has the same effect on the position

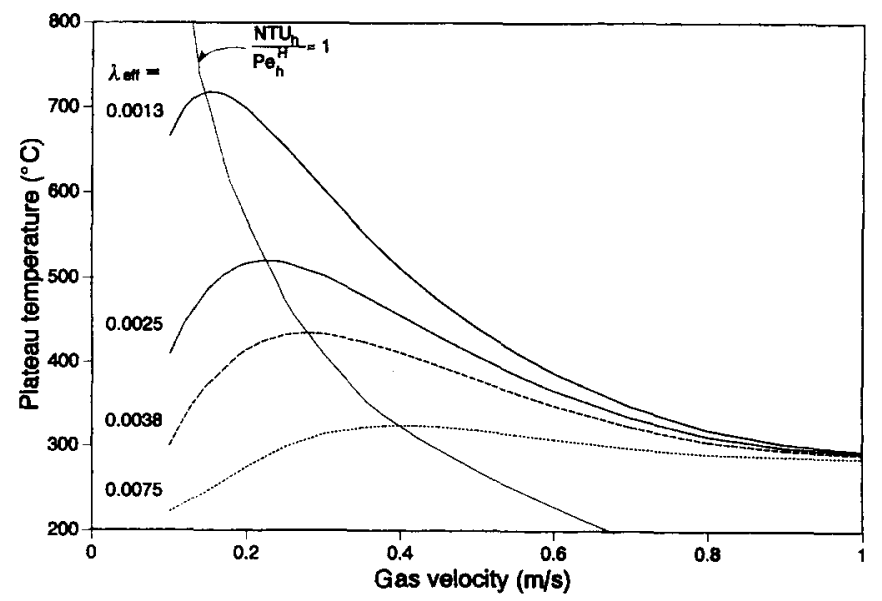

Fig. 7. Influence of the gas velocities on the plateau temperature for different values of the axial dispersion coefficient; conditions see Table 1. of the maximum as changing $\lambda_{\text {eff }}$. The dotted line in Fig. 7 represents the maxima for different axial dispersion coefficients and can be described by the following equation:

$\frac{\mathrm{NTU}_{\mathrm{h}}}{\mathrm{Pe}_{\mathrm{h}}^{\mathrm{H}}}=$ constant $\approx 1$.

This means that the maximum in the plateau temperature is found for a particular gas velocity where $\mathrm{NTU}_{\mathrm{h}}$ is equal to $\mathrm{Pe}_{h}^{\mathrm{H}}$. If $\mathrm{NTU}_{\mathrm{h}}$ is smaller than $\mathrm{Pe}_{\mathrm{h}}^{\mathrm{H}}$ heat transport is more important and the reactor operates on the right hand side of the maximum. If axial dispersion is more important, $\mathrm{Pe}_{\mathrm{h}}^{\mathrm{H}}<\mathrm{NTU}_{\mathrm{h}}$, the reactor operates on the left hand side of the maximum.

The approximations given by Eqs (9) and (10) are not able to describe these maxima and predict in all cases an increase in plateau temperature with increasing gas velocity. The pseudo-homogeneous model and the CCR model are both able to predict these maxima at the same gas velocities as the heterogeneous model does. If the pseudo-homogeneous model is used the equivalence criteria have to be applied. In that case a maximum in $\mathrm{Pe}_{h}^{\mathrm{PH}}$ is found where $\mathrm{Pe}_{\mathrm{h}}^{\mathrm{H}}$ and $\mathrm{NTU}_{\mathrm{h}}$ are approximately equal, thus for such a value of the gas velocity where Eq. (11) is satisfied. As known from the literature - see e.g. Eigenberger and Nieken [6] - increasing the Peclet number or decreasing the axial dispersion coefficient causes an increase in the plateau temperature. So the maximum in the plateau temperature is found where a maximum occurs in $\mathrm{Pe}_{\mathrm{h}}^{\mathrm{PH}}$. Using literature correlations to calculate the heat transport properties in a packed bed, the maximum is found for low gas velocities. So under industrial conditions the reactor will operate on the right hand side of the maximum, where interparticle heat transport is more important than axial dispersion.

Due to the high heat capacity of the solid phase the response of the reactor to fluctuations in inlet concentrations is slow. In Fig. 8 the conversion and maximum temperature are giv-

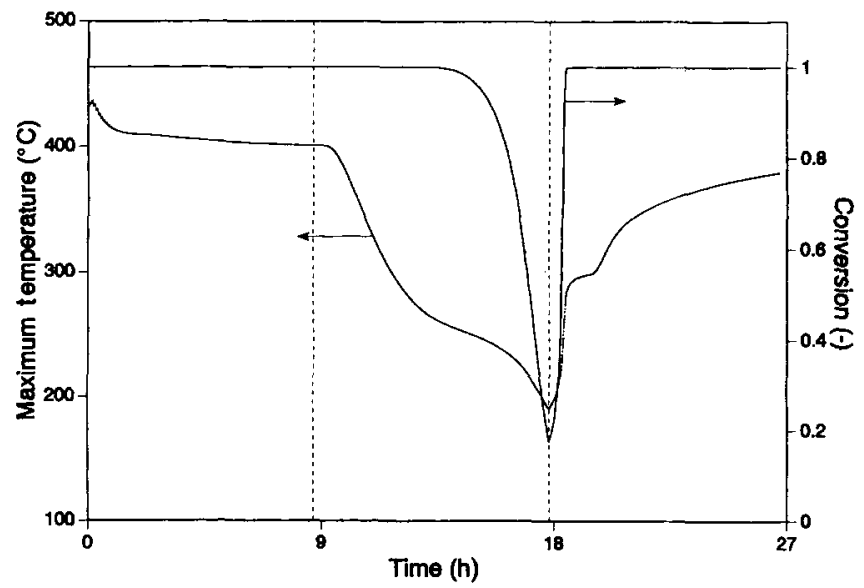

Fig. 8. The maximum temperature and conversion as a function of time. At $t=8.6 \mathrm{~h}: \Delta T_{\text {ad }}: 34.2 \rightarrow 5{ }^{\circ} \mathrm{C}$ and at $t=17.8 \mathrm{~h}: \Delta T_{\text {ad: }}$ : $5 \rightarrow 34.2{ }^{\circ} \mathrm{C}$; conditions see Table 1 . 
en as a function of time. At $t=8.5 \mathrm{~h}$ the concentration of propane in the feed is reduced to a value that is too low the adiabatic temperature rise changes from 34.2 to $5 \mathrm{~K}-$ so that in the PSS the reactor will be blown out. Almost immediately after the decrease in concentration the maximum temperature decreases, meanwhile it takes approximately $5 \mathrm{~h}$ before the conversion starts decreasing. After changing back to the original concentration the system again returns in less than half a hour to full conversion whereas reaching the PSS take much longer. This can be explained as follows: before the conversion can decrease much heat has to be removed from the solid phase by the gaseous outlet stream, which is a slow process. The reaction itself proceeds in the hottest region of the reactor and so, after resetting the inlet concentration, the reaction heat is released in exactly the place where it is needed. Thus full conversion is obtained again relatively quickly.

\subsection{The Plateau Temperature}

The plateau temperature as calculated rigorously with the dynamic heterogeneous model has been compared to those obtained with the approximations of the PSS mentioned earlier. In these simulations process parameters like gas velocity, cycle period, $\lambda_{\text {eff }}$, chemical composition and concentrations are varied. In Fig. 9 the results are given for the approximations described by the analytical expressions (9) and (10). The estimate obtained from an analysis of the relaxed steady state is referred to as RSS and that obtained from an analysis of the heat front is referred to as HFA. It follows that for a quantitative study the errors can exceed $300 \mathrm{~K}$, or more than $40 \%$ on the absolute temperature scale.

In Fig. 10 the estimate of the plateau temperature obtained from the countercurrent reactor model is compared to the heterogeneous model and deviations are less than $10 \%$ on the absolute temperature scale. The largest deviations are found in the case of large cycle periods. This is to be expect-

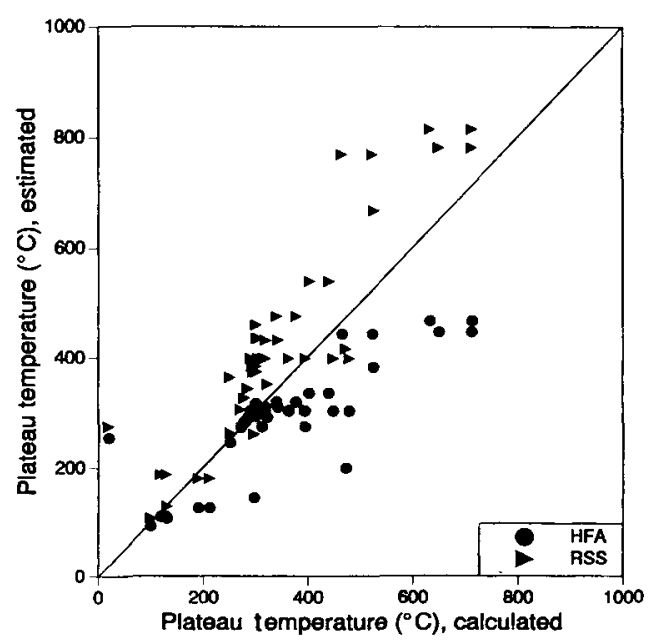

Fig. 9. Comparison between the plateau temperature calculated with the dynamic model and the approximations RSS; analysis of the sliding regime and HFA; analysis of the heat front.

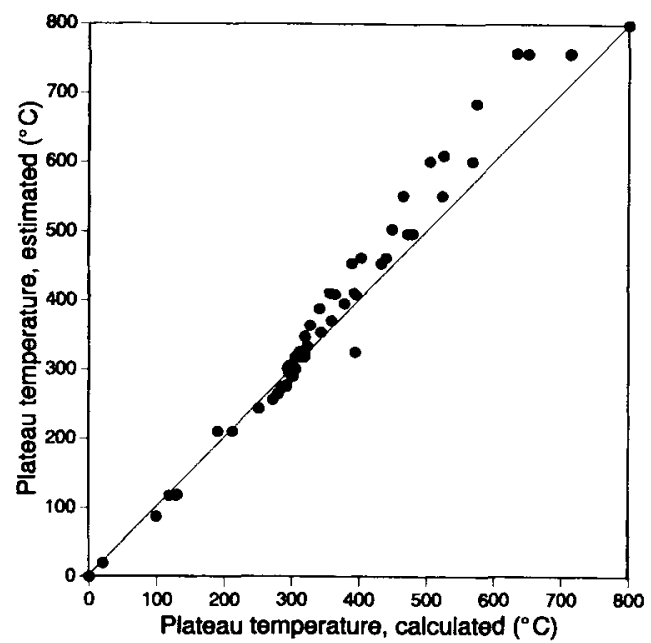

Fig. 10. Comparison between the plateau temperature calculated with the dynamic model and the approximation obtained from the CCR model.

ed as the influence of the cycle period is not accounted for in the CCR model, because its derivation (Eigenberger and Nieken [28]) is based on an infinitely short cycle time. This is further illustrated in Fig. 11 where the plateau temperature is given as a function of the cycle period. The cycle period is here defined as the fraction of "the residence time of the heat wave" in the reactor. In all cases the CCR model predicts the same plateau temperature, whereas the dynamic model exhibits a decrease of the plateau value with increasing cycle periods. The CCR model is able to predict blowout of the reactor at specific conditions. This is shown in Fig. 12 where the plateau temperature is plotted versus the adiabatic temperature rise. The critical minimum adiabatic temperature rise is well predicted by the CCR model; the absolute difference with the rigorous dynamic calculations is less than $1 \mathrm{~K}$ in this specific case. The temperature profiles calculated with both models were also compared. For short cycle periods the CCR model predicts the profiles obtained with the rigorous dynamic model accurately. Thus the pre-

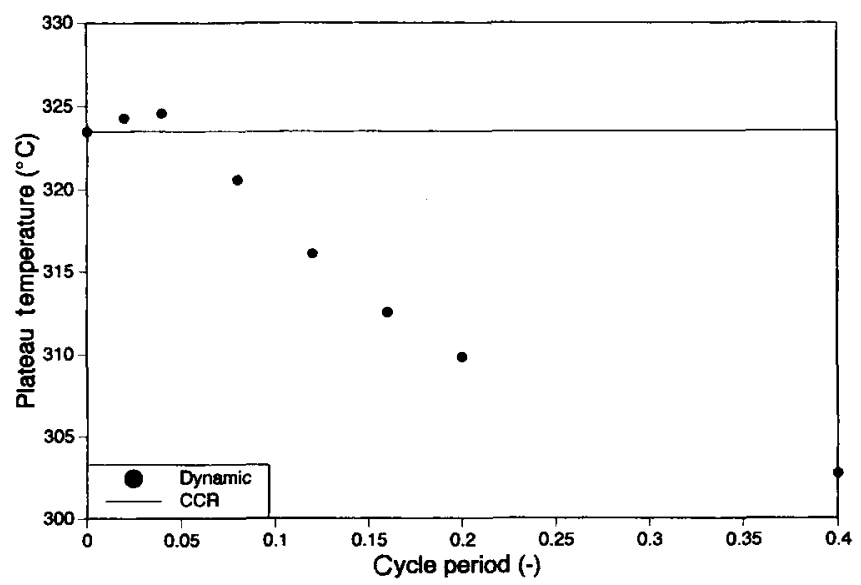

Fig. 11. Comparison between the plateau temperature calculated with the dynamic model and the CCR model as a function of the cycle period; conditions see Table 1 . 


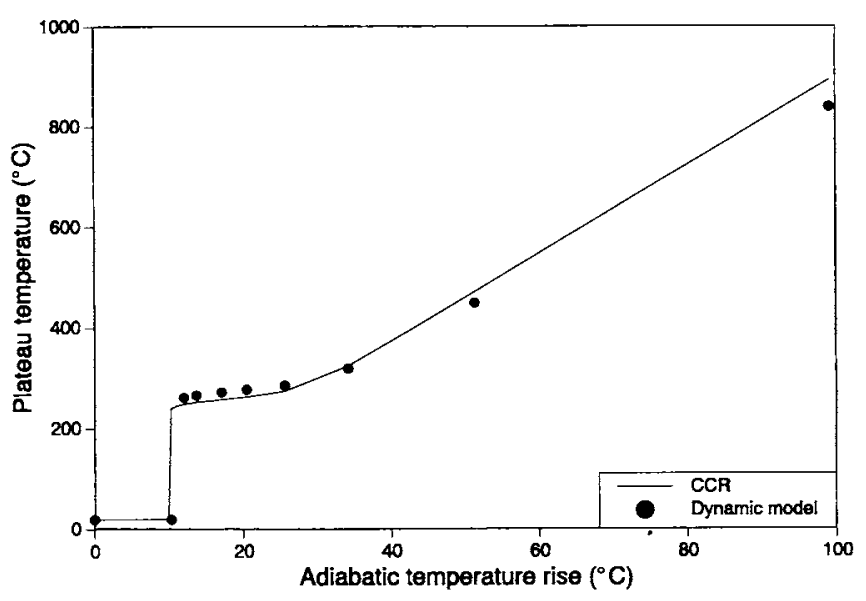

Fig. 12. Plateau temperature as a function of the adiabatic temperature rise: Prediction of blow-out by using the CCR model; conditions see Table 1.

dictions of the CCR model can be used as initial conditions for the rigorous dynamic calculations, thus saving much computer time.

\section{Conclusions}

We can conclude that it is possible to purify waste air in a reverse flow reactor with autothermal operation i.e. without external energy supply, even at very low contaminant concentrations. To ensure autothermal conditions a minimum adiabatic temperature rise (concentration multiplied by heat effect) is needed. Thus components with a high heat of combustion can be handled at lower concentrations.

A reverse flow reactor can handle fluctuations in inlet conditions well, complete conversion is still maintained for a long period of time after the feed concentration has dropped below the blow-out value.

In modelling a reverse flow reactor both a heterogeneous or a pseudo-homogeneous model can be used. If the latter model is used the computer time required is reduced by 10 to $20 \%$. The best short-cut method for the pseudosteady-state is the CCR model. Especially for short cycle periods the agreement between dynamic calculations and the CCR model is good. To save computer time the profiles calculated with the CCR model can be used as the initial profiles in dynamic calculations.

\section{Future Work}

Model calculations are useful only if they are able to predict reality well. In an experimental installation we will compare the model calculations and experimental results. In the experimental reverse flow reactor the catalytic combustion of several organic components of different chemical character will be studied.

\section{Acknowledgement}

These investigations have been supported by the Netherlands' Foundation for Chemical Research (SON) with financial aid from the Netherlands' Technology Foundation and DSM.

Received: June 24, 1993 [CET 576]

\section{Symbols used}

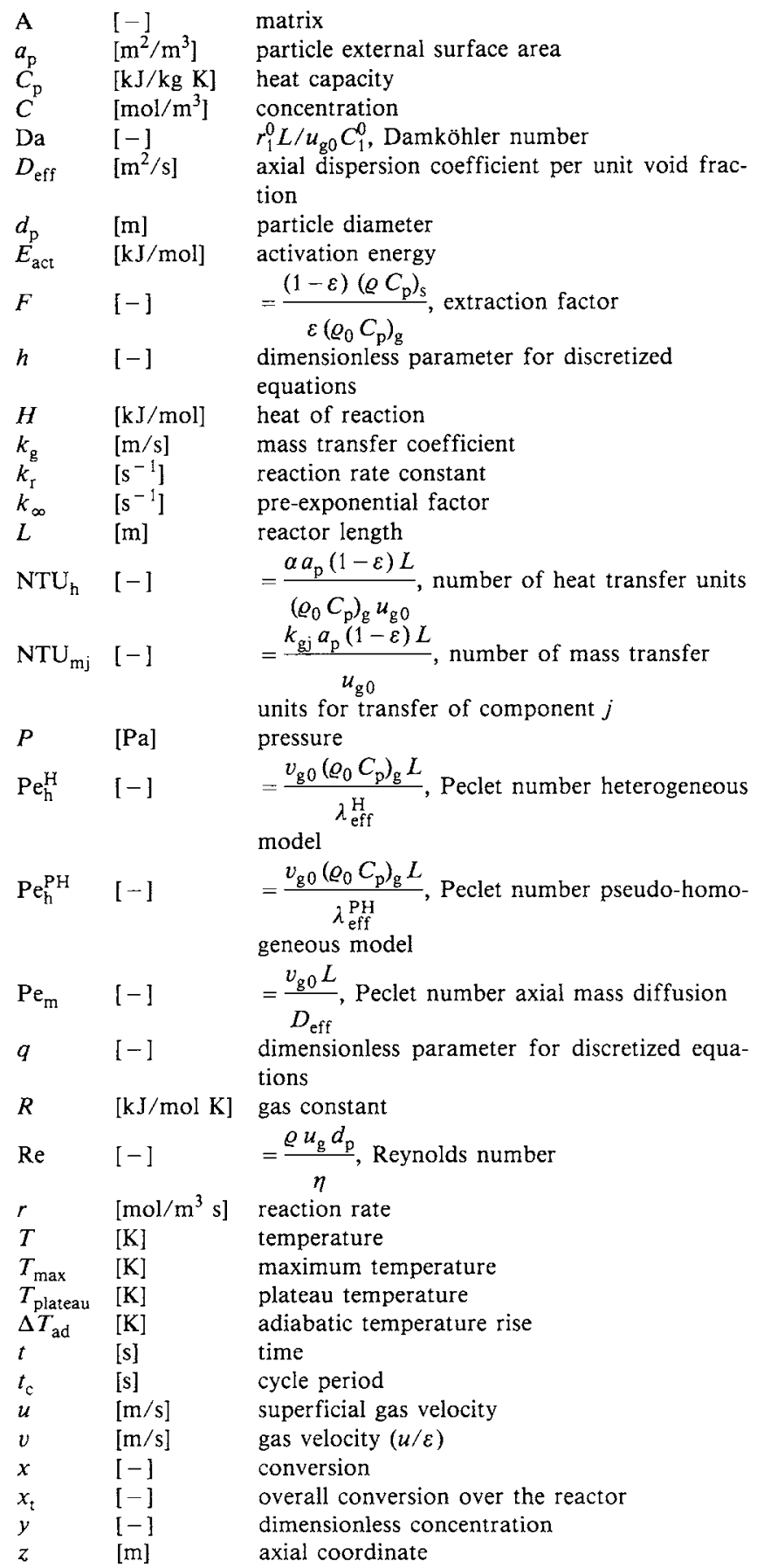




\section{Greek symbols}

\begin{tabular}{|c|c|c|}
\hline$\alpha$ & {$\left[\mathrm{kW} / \mathrm{m}^{2} \mathrm{~K}\right]$} & heat transfer coefficient for the particle \\
\hline$\varepsilon$ & {$[-]$} & bed porosity \\
\hline$\varrho$ & {$\left[\mathrm{kg} / \mathrm{m}^{3}\right]$} & density \\
\hline$\lambda_{\text {eff }}$ & {$[\mathrm{kW} / \mathrm{m} \mathrm{K}]$} & $\begin{array}{l}\text { effective axial thermal conductivity per unit } \\
\text { void fraction } \\
T T\end{array}$ \\
\hline$\theta$ & {$[-]$} & $=\frac{I}{T_{0}}$, dimensionless temperature \\
\hline$\theta_{\text {plateau }}$ & {$[-]$} & $=\frac{T_{\text {plateau }}}{T_{0}}$, dimensionless plateau temperature \\
\hline$\theta_{\text {act }}$ & [-] & $=\frac{E_{\text {act }}}{R T_{0}}$, dimensionless activation temperature \\
\hline$\Delta \theta_{\mathrm{ad}}$ & {$[-]$} & $\begin{array}{l}=\frac{H_{1} C_{1}^{0}}{\left(\varrho C_{\mathrm{p}}\right)_{\mathrm{g}} T_{0}} \text {, dimensionless adiabatic tempera- } \\
\text { ture rise }\end{array}$ \\
\hline$\theta_{\text {out }}$ & {$[-]$} & outlet temperature \\
\hline$\omega$ & {$[-]$} & $=\frac{z}{L}$, dimensionless axial coordinate \\
\hline$\tau$ & {$[-]$} & $=\frac{u_{\mathrm{g} 0} t}{\varepsilon L} \frac{1}{F}$, dimensionless time \\
\hline$\tau_{\mathrm{c}}$ & {$[-]$} & $=\frac{u_{\mathrm{g} 0} t_{\mathrm{c}}}{\varepsilon L} \frac{1}{F}$, dimensionless cycle period \\
\hline
\end{tabular}

\section{Subscripts}

g
$\mathbf{j}$
$\mathbf{m}$
$\mathbf{M}$
$\mathbf{S}$
0
1
2

\section{Superscripts}

H
PH
m
M
n
0
$*$

\section{References}

[1] Boreskov, G.K., Matros, Yu.Sh., Ivanov, A.G., Dokl. Chem. Technol. 288 (1986) pp. 55-59.

[2] Matros, Yu.Sh., Angew. Chem. Int. Ed. Engl. 29 (1990) pp. $1235-1245$.

[3] Matros, Yu.Sh., Unsteady State Processes in Catalysis: Proc. of the International Conference, 5-8 June 1990, Novosibirsk, U.S.S.R., V.S.P. BV, Utrecht, The Netherlands, pp. 131- 164.

[4] Matros, Yu.Sh., Chem. Eng. Sci. 45 (1990) pp. $2097-2102$.

[5] Matros, Yu.Sh., Noskov, A.S., Chumachenko, V.A., Goldman, O.V., Chem. Eng. Sci. 43 (1988) pp. $2061-2066$.

[6] Eigenberger, G., Nieken, U., Chem. Eng. Sci. 43 (1988) pp. $2109-2115$.

[7] Eigenberger, G., Nieken, U., Chem.-Ing.-Tech. 60 (1988) pp. $924-933$.
[8] Chumachenko, V.A., Matros, Yu.Sh., Unsteady State Processes in Catalysis: Proc. of the International Conference, 5-8 June 1990, Novosibirsk, U.S.S.R., V.S.P. BV, Utrecht, The Netherlands, pp. $605-612$.

[9] Noskov, A.S., Ivanov, A. G., Unsteady State Processes in Catal. ysis: Proc. of the International Conference, 5-8 June 1990, Novosibirsk, U.S.S.R., V.S.P. BV, Utrecht, The Netherlands, pp. 535-542.

[10] Sapundzhiev, C., Grozev, G., Elenkov, D., Chem. Eng. Technol. 14 (1991) pp. $209-212$.

[11] Zagoruiko, A. N., Unsteady State Processes in Catalysis: Proc. of the International Conference, 5-8 June 1990, Novosibirsk, U.S.S.R., V.S.P. BV, Utrecht, The Netherlands, pp. 705-712.

[12] Neophytides, S. G., Froment, G.F., Ind. Eng. Chem. Res. 31 (1992) pp. 1583-1589.

[13] Thullie, J., Burghardt, A., Unsteady State Processes in Catalysis: Proc. of the International Conference, 5-8 June 1990, Novosibirsk, U.S.S.R., V.S.P. BV, Utrecht, The Netherlands, pp. $687-692$.

[14] Boreskov, G.K., Bunimovich, G.A., Matros, Yu. Sh., Zolotarskii, N.A., Kiselev, O.V., Dokl. Chem. Technol. 268 (1982) pp. $15-18$.

[15] Bunimovich, G.A., Strots, V.O., Goldman, O.V., Unsteady State Processes in Catalysis: Proc. of the International Conference, 5-8 June 1990, Novosibirsk, U.S.S.R., V.S.P. BV, Utrecht, The Netherlands, pp. 7-24.

[16] Silveston, P. L., Hudgins, R. R., Bogdashev, S., Vernijakovskaja, N., Matros, Yu. Sh., Unsteady State Processes in Catalysis: Proc. of the International Conference, 5-8 June 1990, Novosibirsk, U.S.S.R., V.S.P. BV, Utrecht, The Netherlands, pp. 557-570.

[17] Sapundzhiev, C., Grozev, G., Elenkov, D., Chem. Eng. Technol. 13 (1990) pp. $131-135$.

[18] Gawdzik, A., Rakowski, L., Chem. Eng. Sci. 43 (1988) pp. $3023-3030$.

[19] Gawdzik, A., Rakowski, L., Comput. Chem. Eng. 13 (1989) pp. $1165-1173$.

[20] Bhatia, S. K., Chem. Eng. Sci. 46 (1991) pp. 361-367.

[21] Boreskov, G.K., Matros, Yu.Sh., Kiselev, O.V., Kinet. Catal. 20 (1979) pp. 636-641.

[22] Young, B., Hildebrandt, D., Glasser, D., Chem. Eng. Sci. 47 (1992) pp. $1825-1837$.

[23] Vortmeyer, D., Schaefer, R.J., Chem. Eng. Sci. 29 (1974) pp. $485-491$.

[24] Boreskov, G.K., Bunimovich, G.A., Matros, Yu.Sh., Ivanov, A. A., Kinet. Catal. 23 (1982) pp. 335-338.

[25] Chumakova, N.A., Zolotarskii, I.A., Unsteady State Processes in Catalysis: Proc. of the International Conference, 5-8 June 1990, Novosibirsk, U.S.S.R., V.S.P. BV, Utrecht, The Netherlands, pp. $477-484$.

[26] Matros, Yu.Sh., Studies in Surface Science and Catalysis 22, Elsevier, Amsterdam, 1985.

[27] Matros, Yu.Sh., Studies in Surface Science and Catalysis 43, Elsevier, Amsterdam, 1989.

[28] Eigenberger, G., Nieken, U., Chem.-Ing.-Tech. 63 (1991) pp. $781-791$.

[29] Khanna, R., Seinfeld, J.H., Adv. Chem. Eng. 13 (1988) pp. $113-191$.

[30] Barresi, A.A., Mazzarino, I., Baldi, G., Can. J. Chem. Eng. 70 (1992) pp. $286-293$.

[31] Barresi, A.A., Baldi, G., Chem. Eng. Sci. 47 (1992) pp. $1943-1953$.

\section{Appendix A: Numerical Method}

The heterogeneous model, the pseudo-homogeneous model as well as the countercurrent reactor model comprises a set of non-linear ordinary differential equations and non-linear algebraic equations which can only be solved numerically. 
In this appendix we will discuss the finite difference technique which has been applied to solve these equations.

For the first derivative, a second order upwind scheme is used, because it has a better stability and is more accurate than a first order scheme. The discretisation at point $m-$ see also Fig. 13 - can be written as:

$\frac{\mathrm{d} y}{\mathrm{~d} z}=\frac{y_{\mathrm{m}-2}-h^{2} y_{\mathrm{m}-1}+\left(h^{2}-1\right) y_{\mathrm{m}}}{h(h-1) \Delta z_{\mathrm{m}}}$

with $h=\frac{z_{\mathrm{m}}-z_{\mathrm{m}-2}}{z_{\mathrm{m}}-z_{\mathrm{m}-1}}$ and $\Delta z_{\mathrm{m}}=z_{\mathrm{m}}-z_{\mathrm{m}-1}$ for an equally spaced grid $h=2$, thus

$\frac{\mathrm{d} y}{\mathrm{~d} z}=\frac{y_{\mathrm{m}-2}-4 y_{\mathrm{m}-1}+3 y_{\mathrm{m}}}{2 \Delta z}$.

The second order derivative at point $\mathrm{m}$ is discretised as follows:

$\frac{\mathrm{d}^{2} y}{\mathrm{~d} z^{2}}=2 \frac{q y_{\mathrm{m}-1}-(q+1) y_{\mathrm{m}}+y_{\mathrm{m}+1}}{q(1+q) \Delta z_{\mathrm{m}}^{2}}$

with $q=\frac{z_{\mathrm{m}+1}-z_{\mathrm{m}}}{z_{\mathrm{m}}-z_{\mathrm{m}-1}}$ for an equidistant grid $q$ equals one.

It will be shown how the finite difference technique described above is applied to the dynamic heterogeneous model; for the nomenclature see Fig. 14. Discretisation of the solid phase heat balance with the aid of Eq. (A2) gives:

$$
\begin{aligned}
& \frac{\theta_{\mathrm{s}, \mathrm{m}}^{\mathrm{n}-1}-4 \theta_{\mathrm{s}, \mathrm{m}}^{\mathrm{n}}+3 \theta_{\mathrm{s}, \mathrm{m}}^{\mathrm{n}+1}}{2 \Delta \tau}=\mathrm{NTU}_{\mathrm{h}}\left(\theta_{\mathrm{g}, \mathrm{m}}^{\mathrm{n}+1}-\theta_{\mathrm{s}, \mathrm{m}}^{\mathrm{n}+1}\right)+ \\
& \quad+\mathrm{Da} \Delta \theta_{\mathrm{ad}} \sum r_{\mathrm{j}, \mathrm{m}}^{*, n+1} H_{\mathrm{j}}^{*}
\end{aligned}
$$

which can be rewritten as:

$\theta_{\mathrm{s}, \mathrm{m}}^{\mathrm{n}+1}=$

$$
=\frac{\frac{4}{2 \Delta \tau} \theta_{\mathrm{s}, \mathrm{m}}^{\mathrm{n}}-\frac{1}{2 \Delta \tau} \theta_{\mathrm{s}, \mathrm{m}}^{\mathrm{n}-1}+\mathrm{NTU}_{\mathrm{h}} \theta_{\mathrm{g}, \mathrm{m}}^{\mathrm{n}+1}+\mathrm{Da} \Delta \theta_{\mathrm{ad}} \sum r_{\mathrm{j}, \mathrm{m}}^{*, n+1} H_{\mathrm{j}}^{*}}{\frac{3}{2 \Delta \tau}+\mathrm{NTU}_{\mathrm{h}}}
$$

With the aid of Eqs (A1) and (A3) the gas phase heat balance can be discretised as follows:

$$
\begin{aligned}
0= & -\frac{\theta_{\mathrm{g}, \mathrm{m}-2}^{\mathrm{n}+1}-h^{2} \theta_{\mathrm{g}, \mathrm{m}-1}^{\mathrm{n}+1}+\left(h^{2}-1\right) \theta_{\mathrm{g}, \mathrm{m}}^{\mathrm{n}+1}}{h(h-1) \Delta \omega_{\mathrm{m}}}- \\
& -\operatorname{NTU}_{\mathrm{h}}\left(\theta_{\mathrm{g}, \mathrm{m}}^{\mathrm{n}+1}-\theta_{\mathrm{s}, \mathrm{m}}^{\mathrm{n}+1}\right)+ \\
& +\frac{2}{\mathrm{Pe}} \frac{q \theta_{\mathrm{g}, \mathrm{m}-1}^{\mathrm{n}+1}-(q+1) \theta_{\mathrm{g}, \mathrm{m}}^{\mathrm{n}+1}+\theta_{\mathrm{g}, \mathrm{m}+1}^{\mathrm{n}+1}}{q(1+q) \Delta \omega_{\mathrm{m}}^{2}}
\end{aligned}
$$

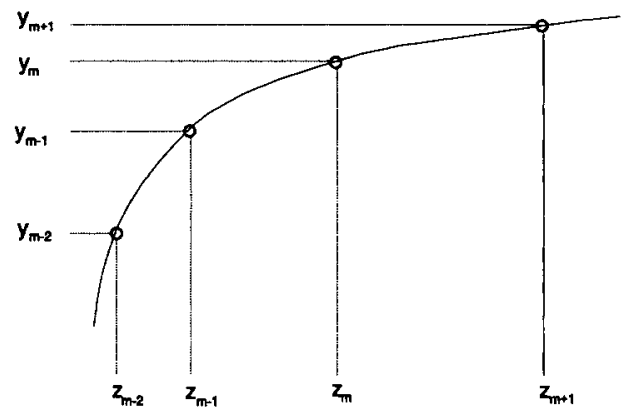

Fig. 13. Positions of the grid points used for the finite difference method.

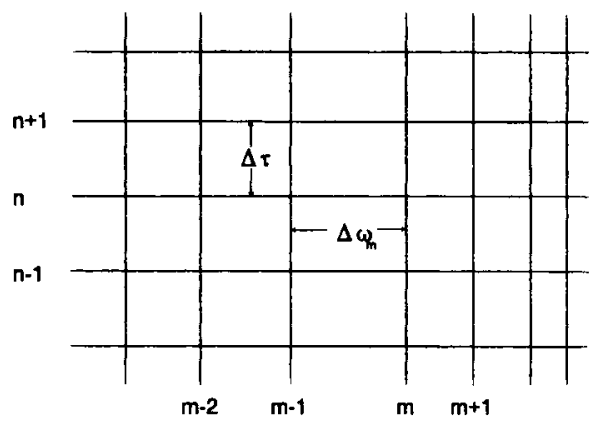

Fig. 14. The grid and nomenclature used for the finite difference method.

Rewriting the equation obtained on substituting Eq. (A 5) into Eq. (A6) yields:

$\frac{1}{h(h-1) \Delta \omega_{\mathrm{m}}} \theta_{\mathrm{g}, \mathrm{m}-2-}^{\mathrm{n}+1}$

$-\left(\frac{h^{2}}{h(h-1) \Delta \omega_{\mathrm{m}}}+\frac{2}{\operatorname{Pe}} \frac{q}{q(1+q) \Delta \omega_{\mathrm{m}}^{2}}\right) \theta_{\mathrm{g}, \mathrm{m}-1}^{\mathrm{n}+1}+$

$+\left(\frac{\left(h^{2}-1\right)}{h(h-1) \Delta \omega_{\mathrm{m}}}+\mathrm{NTU}_{\mathrm{h}}\left[1-\frac{\mathrm{NTU}_{\mathrm{h}}}{3 / 2 \Delta \tau+\mathrm{NTU}_{\mathrm{h}}}\right]+\right.$

$\left.+\frac{2}{\operatorname{Pe}} \frac{(q+1)}{q(1+q) \Delta \omega_{\mathrm{m}}^{2}}\right) \theta_{\mathrm{g}, \mathrm{m}}^{\mathrm{n}+1}-\frac{2}{\operatorname{Pe}} \frac{1}{q(1+q) \Delta \omega_{\mathrm{m}}^{2}} \theta_{\mathrm{g}, \mathrm{m}+1}^{\mathrm{n}+1}=$

$=\mathrm{NTU}_{\mathrm{h}}\left(\frac{\frac{4}{2 \Delta \tau} \theta_{\mathrm{s}, \mathrm{m}}^{\mathrm{n}}-\frac{1}{2 \Delta \tau} \theta_{\mathrm{s}, \mathrm{m}}^{\mathrm{n}-1}+\mathrm{Da} \Delta \theta_{\mathrm{ad}} \sum r_{\mathrm{j}, \mathrm{m}}^{*, \mathrm{n}+1} H_{\mathrm{j}}^{*}}{\frac{3}{2 \Delta \tau}+\mathrm{NTU}_{\mathrm{h}}}\right]$

Eq. (A7) can be written in terms of a matrix equation:

$A \underline{\theta}_{\mathrm{g}}^{\mathrm{n}+1}=\frac{\mathrm{NTU}_{\mathrm{h}}}{3 / 2 \Delta \tau+\mathrm{NTU}_{\mathrm{h}}} \times$

$\times\left(\frac{4}{2 \Delta \tau} \theta_{\mathrm{s}}^{\mathrm{n}}-\frac{1}{2 \Delta \tau} \underline{\theta}_{\mathrm{s}}^{\mathrm{n}-1}+\mathrm{Da} \Delta \theta_{\mathrm{ad}} \sum \underline{r}_{\mathrm{j}}^{* \mathrm{n}+1} H_{j}^{*}\right)$. 
The matrix $\mathrm{A}$ is a band matrix with a band width of four. On the right hand side of Eq. (A8) only the reaction rate $r_{j}$ has to be evaluated at the new time $n+1$. Assuming first order reaction kinetics the mass balance for the solid phase and for each component can be written as follows:

$0=\mathrm{NTU}_{\mathrm{mj}}\left(y_{\mathrm{jg}, \mathrm{m}}^{\mathrm{n}+1}-y_{\mathrm{js}, \mathrm{m}}^{\mathrm{n}+1}\right)-\frac{R_{\mathrm{j}, \mathrm{m}}^{\mathrm{n}+1}}{r_{1}^{0}} y_{\mathrm{js}, \mathrm{m}}^{\mathrm{n}+1}$

with $R_{\mathrm{j}, \mathrm{m}}^{\mathrm{n}+1}=\mathrm{Da} k_{\infty} e^{\left(-E \mathrm{act} / R T_{\mathrm{s}, \mathrm{m}}^{\mathrm{n}+1}\right)} C_{1}^{0}$. Rewriting this equation gives:

$y_{\mathrm{js}, \mathrm{m}}^{\mathrm{n}+1}=\frac{\mathrm{NTU}_{\mathrm{mj}} y_{\mathrm{jg}, \mathrm{m}}^{\mathrm{n}+1} r_{1}^{0}}{\mathrm{NTU}_{\mathrm{m} \mathrm{j}} r_{1}^{0}+R_{\mathrm{j}, \mathrm{m}}^{\mathrm{n}+1}}$.

Using Eqs (A 1) and (A3) the discretisation of the gas phase mass balance for component $j$ can be obtained:

$0=$

$$
\begin{aligned}
& \frac{u_{\mathrm{g}, \mathrm{m}-2}^{\mathrm{n}+1} y_{\mathrm{jg}, \mathrm{m}-2}^{\mathrm{n}+1}-h^{2} u_{\mathrm{g}, \mathrm{m}-1}^{\mathrm{n}+1} y_{\mathrm{j}, \mathrm{m}-1}^{\mathrm{n}+1}+\left(h^{2}-1\right) u_{\mathrm{g}, \mathrm{m}}^{\mathrm{n}+1} y_{\mathrm{jg}, \mathrm{m}}^{\mathrm{n}+1}}{h(h-1) \Delta \omega_{\mathrm{m}}}- \\
& -\mathrm{NTU}_{\mathrm{mj}}\left(y_{\mathrm{jg}, \mathrm{m}}^{\mathrm{n}+1}-y_{\mathrm{js}, \mathrm{m}}^{\mathrm{n}+1}\right)+ \\
& +\frac{2}{\mathrm{Pe}_{\mathrm{m}}} \frac{q y_{\mathrm{jg}, \mathrm{m}-1}^{\mathrm{n}+1}-(q+1) y_{\mathrm{jg}, \mathrm{m}}^{\mathrm{n}+1}+y_{\mathrm{gj}, \mathrm{m}+1}^{\mathrm{n}+1}}{q(1-q) \Delta \omega_{\mathrm{m}}^{2}}
\end{aligned}
$$

Substitution of Eq. (A10) into Eq. (A11) and rearranging the expression obtained yields:

$$
\begin{aligned}
0= & \frac{u_{\mathrm{g}, \mathrm{m}-2}^{\mathrm{n}+1}}{h(h-1) \Delta \omega_{\mathrm{m}}} y_{\mathrm{jg}, \mathrm{m}-2}^{\mathrm{n}+1} \\
& -\left(\frac{h^{2} u_{\mathrm{g}, \mathrm{m}-1}^{\mathrm{n}+1}}{h(h-1) \Delta \omega_{\mathrm{m}}}+\frac{2}{\mathrm{Pe}_{\mathrm{m}}} \frac{q}{q(1+q) \Delta \omega_{\mathrm{m}}^{2}}\right) y_{\mathrm{jg}, \mathrm{m}-1}^{\mathrm{n}+1}+ \\
& +\left(\frac{\left(h^{2}-1\right) u_{\mathrm{g}, \mathrm{m}}^{\mathrm{n}+1}}{h(h-1) \Delta \omega_{\mathrm{m}}}+\right. \\
& \left.+\mathrm{NTU}_{\mathrm{mj}}\left[1-\frac{\mathrm{NTU}_{\mathrm{mj}}}{\mathrm{NTU}_{\mathrm{mj}}+R_{\mathrm{j}, \mathrm{m}}^{\mathrm{n}+1 / r_{0}}}\right]\right) x_{\mathrm{gj}, \mathrm{m}}^{\mathrm{n}+1}-
\end{aligned}
$$

$$
-\frac{2}{\mathrm{Pe}_{\mathrm{m}}} \frac{1}{q(1+q) \Delta \omega_{\mathrm{m}}^{2}} y_{\mathrm{jg}, \mathrm{m}+1}^{\mathrm{n}+1}
$$

or in matrix notation:

$A \underline{y}_{\mathrm{gj}}^{\mathrm{n}+1}=0$.

Now an initial estimate of the solid phase temperature profile is made and Eqs (A13) and (A10) can be solved. Knowing the conversions and the reaction rates, the right hand side of Eq. (A8) can be calculated and Eq. (A8) is solved. The solid phase temperature is calculated from Eq. (A5) and compared to the initial estimate. The whole process is repeated again until the difference between the calculated and estimated value of $\theta_{\mathrm{s}}$ is smaller than a certain value, usually taken as $10^{-6}$.

The CCR model is solved by applying the same method as described above, but in this model we have three coupled heat balances. It is not possible to eliminate the solid phase temperature from, e.g., the heat balance of gas 1 and to solve these equation. An additional iteration is necessary, because the remaining equation is still related to the heat balance of gas 2 . To eliminate this extra iteration we defined a new vector:

$\underline{\theta}=\left(\theta_{\mathrm{g} 1}^{1}, \theta_{\mathrm{g} 2}^{1}, \theta_{\mathrm{g} 1}^{2}, \theta_{\mathrm{g} 2}^{2}, \ldots, \theta_{\mathrm{g} 1}^{\mathrm{m}}, \theta_{\mathrm{g} 2}^{\mathrm{m}}, \ldots, \theta_{\mathrm{g} 1}^{\mathrm{M}}, \theta_{\mathrm{g} 2}^{\mathrm{M}}\right)$

where $\theta_{\mathrm{g} 1}$ and $\theta_{\mathrm{g} 2}$ are the dimensionless temperatures of gases 1 and 2 respectively and $M$ the total number of grid points. The following matrix equation is then solved:

$$
A \underline{\theta}=\frac{\sum \underline{R}_{\mathrm{j}}}{r_{1}^{0}} \quad \text { with } \quad R_{\mathrm{j}}=\left(R_{\mathrm{j} 1}^{1}, R_{\mathrm{j} 2}^{1}, R_{\mathrm{j} 1}^{2}, R_{\mathrm{j} 2}^{2}, \ldots, R_{\mathrm{j} 1}^{\mathrm{M}}, R_{\mathrm{j} 2}^{\mathrm{M}}\right)
$$

where $R_{\mathrm{j}}=\left(R_{\mathrm{j} 1}^{1}, R_{\mathrm{j} 2}^{1}, R_{\mathrm{j} 1}^{2}, R_{\mathrm{j} 2}^{2}, \ldots, R_{\mathrm{j} 1}^{\mathrm{M}}, R_{\mathrm{j} 2}^{\mathrm{M}}\right)$ and $R_{\mathrm{j} 1}^{\mathrm{m}}$ and $R_{\mathrm{j} 2}^{\mathrm{m}}$ reflect the reaction rates of component $j$ at point $m$ in gases 1 and 2 respectively. The mass balances for gas 1 and 2 and the solid phase 1 and 2 are solved as described by Eqs (A 10) and (A13). Then the same iteration process is applied as described above for solving the dynamic model. 